\title{
Critical Factor of E-Learning Component using HELAM and AHP
}

\author{
Generosa Lukhayu Pritalia $^{1}{ }^{*}$, Djoko Budiyanto Setyohadi ${ }^{1}$, Luciana Triani Dewi ${ }^{2}$ and Sri \\ Kusrohmaniah $^{3}$ \\ ${ }^{1}$ Department of Informatics Engineering, Faculty of Industrial Technology, Atma Jaya Yogyakarta \\ University, Yogyakarta - Indonesia \\ ${ }^{2}$ Department of Industrial Engineering, Faculty of Industrial Technology, Atma Jaya Yogyakarta \\ University, Yogyakarta - Indonesia \\ 3 Department of Psychology, Faculty of Psychology, Gadjah Mada University, Yogyakarta - \\ Indonesia
}

\begin{abstract}
Today's e-learning is an essential component of an education process, especially in higher education. The performance of education process can be improved significantly when higher education applies elearning. Furthermore, much higher educations use e-learning, however many of them fail to use e-learning since they do not investigate the critical component of e-learning which suitable for their institution. This paper proposes how to identify the critical factor of e-learning in higher education using Hexagonal E-learning Assessment Model (HELAM) and Analytic Hierarchy Process (AHP). Using two type of student regarding the use of e-learning, i.e., the student who everyday use e-learning and not. Our study shows that the most critical factor chosen by intense students using e-learning is Course Management factor, while the most critical factor for not intense students is Knowledgeable. From the results of this study can be concluded that the students already have the confidence and ability that are high in using e-learning sites, but support and encouragement are also needed to motivate them in the use of e-learning. Such motivation can be their private lecture site management services as well as support and training so that students can be well-informed about elearning sites.
\end{abstract}

\section{Introduction}

Education is the unification of some elements of teaching, namely: a source of information, ideas, educational material as well as students. Some parts of the element integrate the information technology, this precipitating the birth of ideas about e-learning. E-learning is a teaching and learning system using internet technology to enhance knowledge and performance [1]. Learning using electronic media or e-learning had been already started in the 1970 's [2]. In Indonesia, the use of e-learning started in 1999 and continued to grow to this day. The selection of e-learning interface in the learning media is

* Corresponding author: djoko.bdy@gmail.com 
useful to improve the effectiveness and efficiency of the teaching and learning process, the previous study show that interface is able to influenced user emotion [3]. Social aspects or users such as students and teacher attitude as well as technical aspects such as the quality of the system, the quality of the information and content as well as the quality of service are the important aspects in e-learning. Among these aspects, an identification should be done to investigate which aspect that is worth the careful attention for the e-learning site.

This study adopts the Hexagonal E-learning Assessment Model (HELAM) developed by Ozkan and Koseler [4]. HELAM model is one evaluation model to assess user satisfaction towards a system of e-learning. HELAM is chosen because this model tries to offer judgments on all aspects of the faculty, students, institutions, and systems. The method of Analytic Hierarchy Process (AHP) is the method selected in the decision making on this research. Analytic Hierarchy Process (AHP) is a method used in solving problems that are multi-criteria (MCDM) [5]. The AHP method is a method of decision making which is developed to give priority when several criteria are considered in decision making. AHP method is widely used in earlier studies because of its ability to generate optimal decisions [6]. This study will classify the factors elements based on interests. Furthermore, the result element groups will get a major concern in e-learning.

\section{Literature Review}

Hexagonal E-learning Assessment Model (HELAM) which was conceived by Ozkan, Koseler [4] is a model to evaluate or measure the success of e-learning. Many scoring models e-learning are successful but they did not consider the importance of each aspect of e-learning. An assessment of e-learning in general only focuses on some aspects of the course. Hexagonal E-learning Assessment Model (HELAM) combines all aspects such as the faculty, students, institutions, and systems. Hexagonal in E-learning Assessment Model (HELAM) describes that the success of the e-learning system due to two concepts: social issues and Technical Issues. E-Learning process is open system so it will be influenced by social issue. In the other side, the issue is the technical factors affecting e-learning that emerge within the system itself and the supporting factors are complementary factors of using of e-learning.

According to Ozkan, Koseler [7], HELAM has been developed to evaluate e-learning through six dimensions with two important issues namely (1) social issues: social issues: a perspective (the perspective of) student ( 7 factors), the attitude of the teaching staff (9 factors) and (2) Technical Issues: the quality of the System (11 factors), quality of information (4 factors), quality of service (11 factors) as well as a supporting Factor (4 factors)

Analytical Hierarchy Process (AHP) is one of multi-criteria decision-making models that can help the human's mind frame in which the factor of logic, experience, knowledge, emotions, and sense are optimized into a systematic process [8-10]. AHP (Analytical Hierarchy Process) method is a method of decision making which is developed for granting priority of some alternatives when there are several criteria that should be considered, as well as allowing the decision makers to compose a complex problem into a hierarchy or an integrated set of levels. The AHP method is used to solve complex problems. It is performed by setting the group into a hierarchy. And then, a numeric value is used as a substitute for human perception in doing a comparison to deal with the priority

\section{Research Methodology}

Research methodology in the flowchart shown in the figure below. 


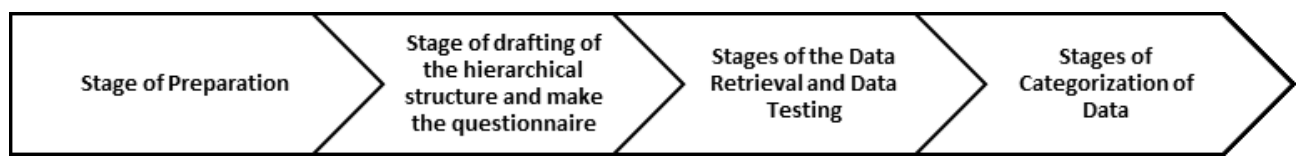

Fig. 1. Research flowchart

\subsection{Stage of Research}

\subsubsection{Stage of Preparation}

Preparation phase includes the study of literature, the design research, the research's time schedule and location, the population and sample. Population samples are grouped into intensive and not intensive students using e-learning website (http://kuliah.uajy.ac.id).

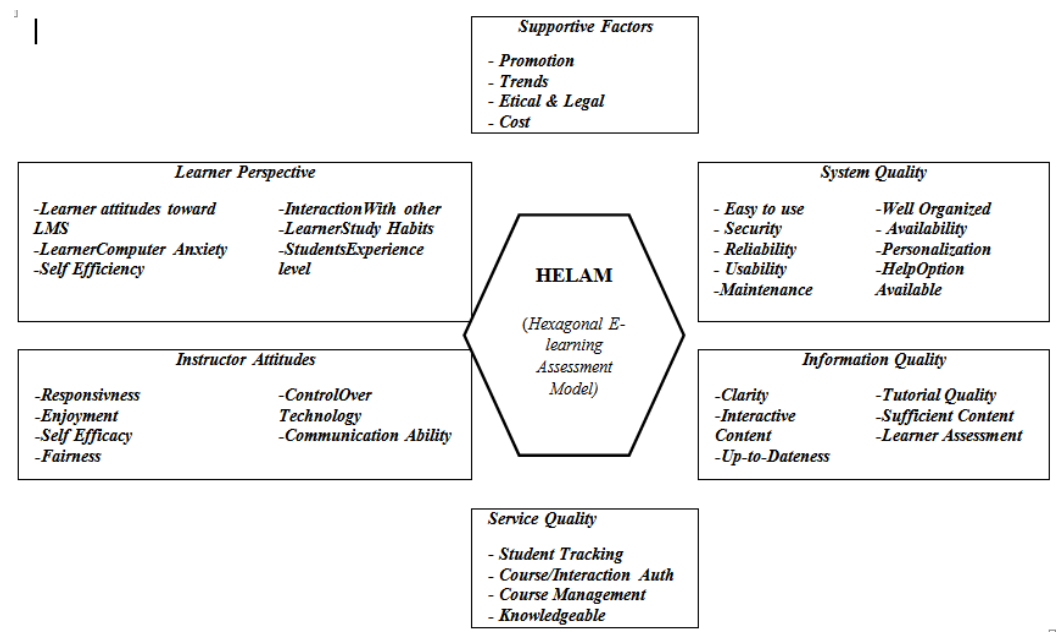

Fig. 2. Hexagonal E-learning Assessment Model

Dimensions and criteria owned HELAM contain some elements that have dependencies or relationships of one criteria to the other. It is contradictory from AHP method because one of the conditions of the method of AHP requires the independent criteria and sub criteria. To overcome these problems, the variable is selected so the used variable is only independent variable. It is shown in Fig 2.

\subsubsection{Stage of drafting of the hierarchical structure and make the questionnaire}

The next step is to create of a hierarchical structure. The creation of hierarchical structure is the basic stage which will be used to solve the problem. After the structure is formed and then a Questionnaire is compiled based on the use of reference questionnaires from AHP (Analytical Hierarchy Process) which was introduced by the Saaty [9]. Preparation of questionnaires is carried out based on the obtained hierarchical structure.

\subsubsection{Stages of the Data Retrieval and Data Testing}

The stage of data retrieval is done by filling out the questionnaires, where the factor priotiry of quiestionare is adopted from Saaty [11]. The sampling method used sampling purposive. 
Determination of the number of samples is 100 relying the common descriptive research [12].

\subsubsection{Stages of Categorization of Data}

Based on the stage of analysis and presentation of data, the next step is to distribute the elements into a class which aims to divide the range into top priority data categories and additional priority categories [13].

\section{Result and Discussion}

\subsection{Data of Respondents}

The data was collected from 146 respondents who student which use e-learning. There were 20 questionnaires that did not return. Based on the demographic data obtained from respondents, the data can be seen in the following table.

Table 1. Respondent demographic data

\begin{tabular}{|c|c|c|c|}
\hline Demographic & Total & Demographic & Total \\
\hline Gender & & Use of the internet for task & \\
\hline Male & 45 & More than 6 hours & 35 \\
\hline Female & 98 & 4-6 hours & 35 \\
\hline Faculty & & 2-4 hours & 60 \\
\hline Industrial Technology & 29 & Less than 2 hours & 16 \\
\hline Economy & 21 & Use of the computer for task & \\
\hline Biology & 25 & More than 6 hours & 42 \\
\hline Social and Political Science & 22 & 4-6 hours & 34 \\
\hline Legal Science & 25 & 2-4 hours & 55 \\
\hline Engineering & 24 & Less than 2 hours & 15 \\
\hline Daily use of internet & & Number of courses that use e-learning & \\
\hline More than 6 hours & 62 & 0 & 18 \\
\hline 4-6 hours & 48 & 1 & 24 \\
\hline 2-4 hours & 31 & 2 & 13 \\
\hline Less than 2 hours & 5 & 3 & 20 \\
\hline Daily use of computer & & 4 & 10 \\
\hline More than 6 hours & 31 & $>4$ & 61 \\
\hline 4-6 hours & 34 & & \\
\hline 2-4 hours & 53 & & \\
\hline Less than 2 hours & 28 & & \\
\hline
\end{tabular}

Based on the results above,this study indicated that the internet has become part of the respondents' everyday life. It is reflected that $75 \%$ of respondents have been accustomed to using the internet for everyday purposes above 4 hours per day. However the use of the internet for the purposes of completing the coursework only gets allocation fewer than 4 hours per day. Thedata reveals that students' attention to use e-learning are likely to be distracted by social media which are more familiar for them and more often to use. The total of respondents can be said to have been wonted to using the sites College because 61 respondents have used the site in College for more than four courses this semester.

\subsection{Data Analysis}

Analysis of questionnaire data from respondents using the AHP method made by Saaty [9]. It can be seen in table 2 that the quality of the system and the quality of information 
basically have a very strong interaction with the quality of the relevant information in the elearning and it is supported by the quality of a good system. The quality of the services that are responsive and appropriate needs is also required so that e-learning can be used optimally by the user. The e-learning system must be effective and efficient [14-16]. The effectiveness and the efficiency of the process are measured from the of user, and it can be used for developing e-learning which is useful to enhance user satisfaction.

Table 2. Dimension ranking between intensive and not intensive students

\begin{tabular}{lllll}
\hline \multirow{2}{*}{ Dimension } & Intensive & \multicolumn{3}{c}{ Not Intensive } \\
\cline { 2 - 5 } & Weights & Ranking & Weights & Ranking \\
\hline Learner Characteristics & 0.1471 & 4 & 0.1435 & 5 \\
Instructor Characteristics & 0.1405 & 5 & 0.1452 & 4 \\
Institution and Service Quality & 0.1896 & 3 & 0.1980 & 3 \\
Infrastructure and System Quality & 0.2330 & 1 & 0.2158 & 1 \\
Course and Information Quality & 0.1907 & 2 & 0.1985 & 2 \\
Extrinsic Motivation & 0.0988 & 6 & 0.0988 & 6 \\
\hline
\end{tabular}

Table 3 shows that the most important factor of the intensive student is course management. For students who are not intensive, a factor that is considered the most important one is knowledge, the factors that are considered most important for not intensive or student are a student's anxiety towards the system.

Table 3. Factor global ranking between intensive and not intensive students

\begin{tabular}{lllllllll}
\hline \multirow{2}{*}{ Factor } & \multicolumn{7}{l}{ Not intensive } & \multicolumn{7}{c}{ Intensive } \\
\cline { 2 - 9 } & $\begin{array}{l}\text { Local } \\
\text { weight }\end{array}$ & $\begin{array}{l}\text { Rank } \\
\text { Local }\end{array}$ & $\begin{array}{l}\text { Global } \\
\text { weight }\end{array}$ & $\begin{array}{l}\text { Rank } \\
\text { Global }\end{array}$ & $\begin{array}{l}\text { Local } \\
\text { weight }\end{array}$ & $\begin{array}{l}\text { Rank } \\
\text { Local }\end{array}$ & $\begin{array}{l}\text { Global } \\
\text { weight }\end{array}$ & $\begin{array}{l}\text { Rank } \\
\text { Global }\end{array}$ \\
\hline Clarity & 0.1656 & 3 & 0.0358 & 7 & 0.2035 & 2 & 0.0474 & 4 \\
Sufficient Content & 0.2030 & 1 & 0.0439 & 4 & 0.2070 & 1 & 0.0482 & 3 \\
Student Tracking & 0.2335 & 3 & & 3 & & 3 & & 5 \\
Course & 0.2435 & 2 & 0.0465 & & 0.2389 & & 0.0455 & \\
$\begin{array}{l}\text { Management } \\
\text { Knowledgeable }\end{array}$ & 0.3443 & 1 & 0.0685 & 1 & 0.2870 & 1 & 0.0547 & 1 \\
\hline
\end{tabular}

\subsection{Categorizing Data}

Data categorization is done through the stages of determining the number of intervals class followed by determining the range of the data and determining the length of the class intervals.

Table 4. Frequency distribution of global weights for intensive and not intensive students

\begin{tabular}{lllllll}
\hline class & Not intensive & & \multicolumn{3}{c}{ Intensive } \\
\cline { 2 - 7 } & Range & Frequency & Rank & Range & Frequency & Rank \\
\hline 1 & $0.0594-0.0685$ & 1 & 1 & $0.0480-0.0547$ & 2 & $1-2$ \\
2 & $0.0502-0.0594$ & 0 & - & $0.0413-0.0480$ & 4 & $3-6$ \\
3 & $0.0410-0.0502$ & 3 & $2-4$ & $0.0346-0.0413$ & 1 & 7 \\
4 & $0.0319-0.0410$ & 7 & $5-11$ & $0.0279-0.0346$ & 9 & $8-16$ \\
5 & $0.0227-0.0319$ & 13 & $12-24$ & $0.0212-0.0279$ & 6 & $17-22$ \\
6 & $0.0135-0.0227$ & 11 & $25-35$ & $0.0145-0.0212$ & 13 & $23-35$ \\
\hline
\end{tabular}

The category of priority is gained from data at the top of the class. The results in table 4 major priority Category obtained from data on class 1 . The table show that the top priority 
for intensive students are: Knowledgeable while the top priority for non intensive students are Course Management and Knowledgeable.

\subsection{Discussion}

The result of table 4 implies that Knowledgeable Service is in the form of instructions and special training given to students to increase the ability of students in utilizing computerbased learning systems and e-learning. This is inline to previous studies of Bhuasiri [17] that computer users and e-learning in developing country institutions have not so acquainted with technologies such as institutions in developed countries. It should be noted that e-learning is not the main need. Therefore, usually e-learning is not well performed [18]. Raising awareness of the importance of technology users, computer usage skills and knowledge is an important factor in the success of e-learning at institutions in the developing countries.

Course Management services should be provided in program settings or materials to serve the needs of students in the education process [19]. Learning materials management services is a service that should be given by the developer or the owner of the system to the users of the system. Material management services are provided for teachers and users to organize and to manage the material needed for a learning activity.

Based on the results of the elements deliberations that became the top priority for students who are intensive and not intensive, there are some suggestions that can be given to the owner and developer of the system in order to optimize the site e-learning, such as :

- Socialization features in the e-learning are increasingly optimized so that the user can find out every feature of the e-learning site. Socialization can be performed by informaton disemanitation from the owner of the system or teachers and fellow students. It will be useful to encourage the students who are not intensive to use e-learning can be done by providing them the required knowledge and training. It will play the importance of using elearning site in learning.

- Optimizing service management courses and materials courses taken by students are available in the system. Increasing the use of e-learning can be encouraged by faculty and students who routinely or even obligated use e-learning in the learning process.

In addition, the most important factor for students foundin the study is a surprising thing Computer anxiety of the system becomes the most unnoticed factor for students who are intensive and not intensive using e-learning. They pay more attention to the technical aspects or factors that are derived from the system rather than the social aspects or factors that is originated from users. The study found that factors that can affect the success of elearning in higher education are related to the improvement of technology and attitude towards e-learning, the increased knowledge and skills of basic technology, content learning improvement, computer training and motivation.

\section{Conclusion}

The results of this study showed that college students have the confidence and ability in using e-learning sites, but they need support and encouragement in motivating. The motivation comes from the owner or developer of the system, teachers and even from fellow students. The study found six dimensions to implement e-learning system in college. These dimensions include the characteristics of student Attitude, the teachers attitude, systems quality, information and content quality as well as the service quality. The most important factor is the course management factor or services provided by the system to manage the courses which are being taken by students and factor in knowledge or services of the owner and developer of the system so that users can become well-informed about the 
e-learning system. Further research should examine and focus on stakeholders'different contexts such as system developer and administrator. The results of this research may change from time to time by the interests of stakeholders. This insight can reveal additional information that is useful for the e-learning application of in college.

\section{References}

1. Ruiz, J.,Mintzer, M., \& Leipzig, RThe Impact of E-Learning in Medical. . (2006).

2. Waller, V., \& Wilson, J. A Definition of E-Learning. (2001).

3. Djoko Budiyanto Setyohadi, Sri Kusrohmaniah, Efrans Christian, Luciana Triani Dewi. M-learning Interface Design Based on Emotional Aspect Analysis. In Paper presented at International Conference on Intelligent Human Computer Interaction, 276-287. (2017).

4. Ozkan, S., \& Koseler, R. Multi-Dimensional Evaluation of E-Learning Systems in the Higher Education Context: An Empirical Investigation of a Computer Literacy Course. (2009).

5. Lee, MC. The Analytic Hierarchy and the Network Process in Multicriteria Decision Making: Performance Evaluation and Selecting Key Performance Indicators Based on ANP Model. Convergence and Hybrid Information Technologies. (2010).

6. Singh, Rana Pratap., Nachtnebel, Hans Peter., Analytical hierarchy process (AHP) application for reinforcement of hydropower strategy in Nepal. Renewable and Sustainable Energy Reviews. (2016).

7. Ozkan, S., Koseler, R., \& Baykal, N. Evaluating learning management systems. (2009).

8. Chen, M. K., \& Wang, S.-C. The critical factors of success for information service industry in developing international market: using analytic hierarchy process (AHP) approach. Expert Systems with Applications, 37(1), 694-704. (2010).

9. Saaty, T.L. Fundamentals of Decision Making and Priority Theory with the Analytic Hierarchy Process.Pittsburgh USA: RWS Publications. (1994).

10. Saaty, T. L. How to Make a Decision The Analytic Hierarchy Process. European Journal of Operational Research, 48, 9-26. (1970).

11. Bozbura, F. T., Beskese, A., \& Kahraman, C. Prioritization of human capital measurement indicators using fuzzy AHP. Expert Systems with Applications, 32(4), 1100-1112. (2007).

12. Fraenkel, J., Wallen, N. How to Design and evaluate research in education $\left(2^{\text {nd }} e d\right)$. New York: McGraw-Hill Inc. (1993).

13. Sturges, Herbert. (The Choice of a Class Interval. Journal of American Statistica Association. 1926).

14. Holsapple, C. W., \& Lee-Post, A. Defining, assessing, and promoting e-learning success: An information systems perspective. Decision Sciences Journal of Innovative Education, 4(1), 67-85. (2006).

15. Selim, H. M. Critical success factors for e-learning acceptance: Confirmatory factor models. International Journal of Technology Marketing. (2007).

16. Sun, P. C., et al. What drives a successful e-learning? An empirical investigation of the critical factors influencing learner satisfaction. Computers Education, 50(4), $1183-$ 1202. (2008).

17. Bhuasiri, Wannasiri; Xaymoungkhoun, Oudone; Zo, Hangjung. Critical Success factors for e-learning in developing countries: A Comparative Analysis between ICT experts and faculty. Journal Computer \& Education. (2012).

18. Djoko Budiyanto Setyohadi, Michael Aristian, Benyamin Langgu Sinaga and Nor Aziati Abdul Hamid. Social Critical Factors Affecting Intentions and Behaviours to 
Use E-Learning: An Empirical Investigation Using Technology Acceptance Model. Asian Journal of Scientific Research, (2017). 10: 271-280.

19. Khan, B. Managing e-learning strategies: Design, delivery, implementation and evaluation. Hershey, London, Melbourne, Singapore: Information Science Publishing. (2005). 